\title{
11. Social accountability, citizenship and social protection in the MENA region: exploring the linkages
}

\author{
Sylvia I. Bergh
}

\section{INTRODUCTION}

This chapter explores the theoretical and empirical linkages between social accountability, citizenship and social protection in the MENA region. It is clear that the popular dissatisfaction with the poor quality of, and corruption in, basic service delivery and social welfare provision represents one of the root causes of the "Arab Spring" uprisings. Both local and national actors as well as external stakeholders including international (aid) organizations have been and are still searching for (cost-)effective ways to address these issues. Social accountability initiatives (SAIs) could provide solutions here as they give more space to the voices of the population and ensure that they reach existing service providers. This in turn can improve the latter's responsiveness to local needs as well as mutual accountability between service users and providers. SAIs mostly aim at improving existing services, rather than advocating for spending more resources on new government institutions or agencies. Apart from considerations of financial affordability, the (perceived or real) urgent need to establish a new "social contract" between citizens and governments in the region also explains the current interest in social accountability initiatives, especially when they are conceived of as instruments to facilitate the claiming of human rights (such as they are enshrined in the Universal Declaration of Human Rights). As Sepúlveda and Nyst (2012:11) assert, "human rights obligations relate not only to the final outcome of social protection programmes, but also to the process through which such programmes are designed and implemented."

Social accountability initiatives can help to contribute to the design and implementation of programmes more transparently and accountably, and ultimately lead to improved service delivery (Grandvoinnet, Aslam and Raha, 2015:61). They can thus - at least in theory - contribute to transformative $^{1}$ social protection measures which address social injustice and exclusion 
as well as vulnerability through the delivery of social services and changing behaviour towards socially vulnerable groups, as well as opening up new spaces for (democratic) participation (see Ait Mansour and Jawad, Chapter 4 , this volume). Indeed, many social accountability (SA) initiatives represent processes by which ordinary people can experience and claim "social citizenship", that is, "the rights and duties associated with the provision of benefits and services designed to meet social needs and enhance capabilities, and [the] guarantee [of] the resources necessary to finance them" (Taylor-Gooby, 2009:4, cited in Jawad, Jones and Messkoub, Chapter 2, this volume). SA initiatives can help to not only (re)build trust between the state and society actors, but also to increase reciprocity and inclusion among citizens. In other words, under certain conditions, they can strengthen both a "vertical" model of citizenship (organized around the relationship between state and society) and a "horizontal model" of citizenship (that is, the rights and obligations that citizens have with regard to each other; Kabeer, 2004, cited in Kabeer, 2014:346). All these conceptions of citizenship are arguably situated within a conventional approach to citizenship studies in which three types of rights (civil, political and social) and three obligations (conscription, taxation and franchise) characterize the relationship between citizen and states. Crucially, citizenship is here considered as membership of the nation-state (Isin, 2017:512-13). However, Engin Isin (ibid.:513) distinguishes this conventional approach from critical approaches to citizenship, which recognize new rights (such as sexual, cultural and environmental rights) and emphasize the fact that rights and obligations are also negotiated through supranational and international institutions such as the United Nations - thereby questioning the assumption that citizenship is membership in only a nation-state. Most importantly, "critical approaches to citizenship draw our attention to a performative understanding of rights" (Isin, 2017:514), that is, they call attention to the citizen as a political subject at the centre of struggles for rights who questions, or even breaks, existing conventions (ibid.:514). Although the empirical evidence is limited, this chapter explores the available evidence as well as the potential for SAIs related to social protection programmes in the MENA region to give space to such struggles and improve development outcomes.

This chapter thus aims to contribute to filling the knowledge gap identified by Green (2012, as cited in Jawad, Jones and Messkoub, Chapter 2 , this volume), that is, to study the ways in which states interact with citizens through the process of policy and service delivery, thereby challenging the narrow (and conventional) conceptualization of citizenship in African (and arguably also Middle East and North African) states which focuses on fiscal citizenship and political accountability. Furthermore, by presenting some promising SA experiences with regard to improving social 
welfare, health and education service delivery in the MENA region, this contribution aims to address the challenge identified by Hickey and King (2016:1236) in their comprehensive meta-evaluation - namely that the evidence base on what shapes SAI effectiveness within social protection interventions is very weak, especially around issues of power and politics. For example, a review including 40 studies on social accountability in health provision did not include a single one from the MENA region, though this is probably partly due to the English-language bias in the sample (Lodenstein et al., 2016:13).

This chapter contributes mainly to the book's second key question, which asks about the existing mechanisms of social inclusion and entitlement currently in place that determine access to social and public services. However, by highlighting the linkages between social protection and notions around citizenship, it also touches on the third key question regarding the potential for solidarity and citizenship promotion as part of more universal social policies in the MENA region. And as one of the examples highlights the gender aspects in a cash transfer (CT) programme, the chapter also makes a (limited) contribution to addressing the book's fourth key question on implications for gender equity.

According to ESCWA (2014:2), "social protection can be broadly defined as the set of programmes and interventions designed to alleviate poverty by supporting and protecting individuals and their families in the event of adverse income shocks, and by providing access to basic social services." The range of social protection schemes can be classified into three main categories, including social insurance, pension schemes and labour market programmes and regulations. A further category, which presents the focus of this chapter, is that of "social assistance schemes funded by public resources (non-contributory), including capacity-building programmes and in-kind or cash transfers" (ibid.) This category also comprises free or low-cost access to basic services such as health care, education and water, for certain poor and vulnerable segments of the population as determined by income and economic means, location or family characteristics (Jawad, 2014:14, cited in ESCWA, 2014:2). Most analysts on the state and political economy of social protection in the MENA region conclude that while all Arab countries have some form of social protection schemes, they are highly fragmented and characterized by a logic of social assistance that seriously limits their impact on social welfare and raises sustainability issues (ESCWA, 2014:5; see also Ait Mansour and Jawad, Chapter 4, this volume; Jawad, Jones and Messkoub, Chapter 2, this volume; Silva, Levin and Morgandi, 2013; Loewe, 2013; ANND, 2014; Batniji et al., 2014; Karshenas, Moghadam and Alami, 2014; Brixi, Lust and Woolcock, 2015; Alami, 2016). 
SA in turn is defined here as "the ongoing and collective effort to hold public officials to account for the provision of public goods which are existing state obligations" (Houtzager and Joshi, 2008:3, cited in Joshi and Houtzager, 2012:150). This definition is useful as it does not conflate SA with citizen participation in policy processes more broadly (but see Chambers, 2014). As Grandvoinnet, Aslam and Raha (2015:32) put it, "participation in policy making enables citizens to express their opinions about what should be done or how something should proceed, but it does not offer any guarantee that officials will heed or follow through on the basis of these views. In contrast, accountability is concerned with public officials having to account for their actions", independent from whether the citizens have been involved in the decision-making related to these actions. The above definition also highlights the dimension of state obligations.

Over the years, a wide range of SA tools and interventions have been developed and implemented (see Grandvoinnet, Aslam and Raha, 2015:293-8). Grandvoinnet, Aslam and Raha (2015:27), distinguish between SA mechanisms which are tailored principally to individual action (such as grievance redress mechanisms - GRMs and citizen report cards), and those which focus more on collective action (such as community scorecards or social audits). The latter consider civic mobilization and collective action on the part of citizens to be an essential component. Furthermore, "SA mechanisms use different modes of citizen engagement with the state, which can be mapped along an axis ranging from collaborative to confrontational [e.g. tools relying on 'naming and shaming' of officials]" (ibid.:28). It is clear that citizens' understandings of citizenship also determines the extent to which they will use SAIs as sites for citizenship struggles to claim (universal) rights.

The recent academic and policy literature has started to develop the linkages between social accountability, citizenship and social protection. For example, Devereux, McGregor and Wheeler (2011, cited in Hickey and King, 2016:1225) claim that for social protection to be transformative it must go beyond the management of risk towards tackling the underlying causes of vulnerability. In order to do so, this chapter argues, social protection interventions should be delivered in ways that enable recipients to exercise agency in holding providers to account for delivering social protection as a right rather than as a hand-out. Indeed, "this move fits with wider calls for both social accountability and social protection to be reconceptualised in terms of a wider project of forging a more just social contract" (Hickey, 2011; Joshi and Houtzager, 2012, cited in Hickey and King, 2016:1225; see also Molyneux, Jones and Samuels, 2016:1093 for a similar argument on CT programmes, and Barca (2015) for an overview of 
demand- and supply-side problems with grievance mechanisms in social protection programmes).

It is clear that moving from (particularistic) assistance-based social protection to (universal) rights-based policies, whereby beneficiaries are considered not as passive recipients of assistance but as autonomous and active agents who can participate in programme design, would greatly contribute to the reform of existing systems in the MENA region (Sepúlveda and Nyst, 2012, cited in ESCWA, 2014:5). This will be particularly challenging however for social protection delivered by Zakat funds, charities and faith-based organizations, as they "tend to have a paternalistic rather than a rights-based approach", and mostly operate without any complaint or accountability mechanisms, whether upward (to the state) or downward (to their "beneficiaries"; ESCWA, 2014:8).

In a promising development, since the Arab uprisings in 2010-11, the revised constitutions of all MENA countries set education as a right for all citizens and, with the exception of Morocco, mandate that basic education is compulsory and free for youth (Brixi, Lust and Woolcock, 2015:22). Similarly, the right of all citizens to health care is to some extent enshrined in the constitutions of all MENA countries except for Djibouti, Jordan and Lebanon (ibid.:22).

However, the assumptions about SAIs outlined above, through which citizens would be able to claim these rights, may be overly optimistic in the socio-political context of most MENA countries. For example, rather than performance, personal relationships (wasta) and (patronage) ties matter most for political and professional careers. As Brixi, Lust and Woolcock (2015:2) point out, "this limits citizens' trust in and formal engagement with public institutions. To fulfil their needs, citizens rely on their own relationships or informal fees [i.e. bribes]." In their in-depth study of the state of service provision across the region, Brixi, Lust and Woolcock (ibid.) argue that "improving the quality of public services will require breaking this cycle of poor performance: making politicians, public servants, and providers accountable to citizens and promoting citizens' trust in and engagement with state institutions." Social accountability is considered to be particularly relevant to contexts where regulation through internal (administrative) accountability measures is weak or where formal political and judicial channels are inaccessible to the majority of citizens, in particular the poor (Shukla, Saha and Jadhav, 2013; Fox, 2015, cited in Lodenstein et al., 2016:2).

Having outlined the overall conceptual linkages and briefly reviewed the regional context, the next two sections present some examples of accountability features in CT programmes, and community scorecard (CSC) processes in the health and education sectors, respectively. These are followed by a discussion section and conclusions. 


\section{SOCIAL ACCOUNTABILITY IN CT PROGRAMMES: SOME EXAMPLES}

Although, as argued above, social accountability needs to be conceptually distinguished from citizen participation in policy and programme design and implementation more generally, it is worth mentioning some examples of citizen participation in social protection policies in the MENA region. At the national level, dialogues on social protection policy have been held in some countries. An example can be found in Jordan where the Jordanian Social Security Corporation initiated a national dialogue on social security reform in 2006 with a wide range of national and local bodies and experts, as well as activists, trade unionists, members of civil society organizations and insured persons. Stakeholders had the opportunity to evaluate the current system and provide feedback and suggestions, many of which were incorporated into the new social security bill passed by Parliament in 2014. The bill represented the first substantial reform of the social insurance scheme in Jordan since social security legislation was passed in 1978 (ESCWA, 2014:18-19).

At the level of cities, ESCWA (2014:17) cites the Al-Madinah Urban Observatory Network in Saudi Arabia, in the municipality of Al-Madinah Al-Munawarah, as an example of a public accountability tool. It was established in 2003 with the help of UNDP and others. The observatory's steering committee is comprised of the Governor of Al-Madinah, 25 members from government departments and representatives from NGOs and the private sector. The observatory is the first facility of its kind in the Arab region and generates data on 107 indicators covering all major aspects of economic, social and human development (such as education, health, poverty and labour), disaggregated by gender. It promotes the notion of "spatial equity", and has also been important for monitoring municipal performance in urban management and service delivery.

As for social accountability features in CT programmes in the MENA region, the evidence is limited to a few case studies. Jones et al. (2016) analyse the Palestinian National Cash Transfer Programme (PNCTP), launched in 2010 in the West Bank and in 2011 in Gaza (see Jones, Samuels and Malachowska, 2013:14) and Yemen's Social Welfare Fund (SWF), launched in 1996. A key constraint to social accountability in the SWF is the lack of information about the fund's key principles and formal complaint mechanisms. "Community leaders [. . .] frequently suffer from limited information about important programme details and linkages to other social protection interventions. These information deficits effectively constrain the accountability of implementing agencies and national government to citizens, and are in turn compounded by citizens' lack of 
information about how the programme operates or its selection criteria" (Jones et al., 2016:1218). A further constraint to exercising SA is the "concern among beneficiaries that they might be sanctioned or taken off the list of beneficiaries if they complain" (ibid.:1218), and as a result, only very few people attempted to complain about the fund to local leaders or SWF staff (Bagash, Pereznieto and Dubai, 2012:59; see also Bagash, Pereznieto and Dubai, 2013 for a brief review of the SWF research findings).

Similarly, in the Palestinian context, opportunities for information exchange and feedback between citizens and programme implementers are limited to interactions (between beneficiaries) on payment days at the banks and to very short home visits by social workers (Jones et al., 2016:1219). In Gaza, complaint boxes are absent, and there are concerns that written or verbal complaints about PNCTP are not reaching senior ministry officials (due to social workers intercepting and/or manipulating the information, and because of the fact that the complaints data management system is not fully computerized). There are no neutral spaces for beneficiaries to express their views about the programme (Jones et al., 2016:1220-1).

However, Jones et al. (2015:15-16) note the establishment of CT beneficiary fora organized by Aman (the Palestinian branch of Transparency International) on behalf of the Ministry of Social Affairs (MoSA) in the West Bank. These fora aim to strengthen opportunities for information exchange between programme implementers and beneficiaries, and enable beneficiaries to voice their concerns in mediated dialogues with key ministry staff. Accompanying activities financed by the Tajaawob programme (see ibid. for details) involved capacity-building support for social workers to strengthen their skillsets to interact constructively and responsively with PNCTP beneficiaries. However, Aman facilitators have to date not been able to prevent better-educated and relatively less vulnerable men from dominating discussions. In addition, the discussions within the beneficiary fora have tended to focus on individual problems (for example, related to benefit amount) rather than collective ones, which in turn undermines their potential to serve as a more institutionalized channel to discuss cross-cutting issues that can then be raised and potentially addressed by programme implementers and senior managers within MoSA.

In contrast to such formal accountability channels, Jones et al. (2016:1222) cite a case of informal community action taken by beneficiaries in Yemen against the manager of a post office who was replaced following prolonged complaints about poor treatment during cash distribution (where some workers were charging "commission" to make the payment). This suggests that at least some beneficiaries have a stronger perception of the CT as a right rather than as a gift, and shows a glimpse of local struggles for citizenship. 
The case studies of CTs by Jones et al. (2016) illustrate the inherent difficulty for such programmes to be accountable to their beneficiaries. As Hickey and King (2016:1235) point out, "the poorest and most vulnerable people who are the main target of social protection interventions are those worst-placed to generate the agency required to mobilise and hold public institutions to account", precisely because "popular agency requires ablebodiedness, an ability to articulate interests in accessible and affordable spaces of governance, and room for manoeuvre within social relationships, all things which are least available to the poorest" (Cleaver, 2005, cited in Hickey and King, 2016:1235). A second challenge stems from the fact that CTs are delivered in ways that may undermine the emergence of collective forms of agency, given both the nature of the good that is delivered and its individuating distribution mechanisms (Hickey and King, 2016:1235, 1237). In other words, programmes which rely solely on beneficiary participation to ensure accountability risk failure (Engberg-Pedersen and Webster, 2002:255-71; Fox, 2015; Mansuri and Rao, 2013; McGee and Norton, 2000, all cited in Molyneux, Jones and Samuels, 2016:1093). Molyneux and colleagues (2016:1094) therefore call for closer attention to administrative forms of accountability to secure transparency and ensure the proper procedures and conduct of officials.

A more promising example of a conditional cash transfer (CCT) programme, where programme design had a stronger built-in focus on agency and rights, can be found in Egypt. In 2009, the Ministry of Social Solidarity (now Social Affairs) partnered with the Social Research Center of the American University in Cairo and the Pathways of Women's Empowerment Research Programme Consortium to pilot a CCT programme in Ain el-Sira, Cairo. The pilot scheme was launched in March 2009 and provided transfers to more than 200 families over more than two years. In August 2010, it was extended to 65 villages in Upper Egypt in the governorates of Sohag and Assiut. The Egyptian revolution began two days after completion of the programme's baseline survey of 7,000 families, and the Ministry of Social Affairs terminated the new programme in March 2012. However, the government started reintroducing it in the same villages of Upper Egypt later on (ESCWA, 2014:19; for the results of a before/after impact evaluation of the programme in Ain el-Sira with regard to outcomes such as work, empowerment, domestic violence and family planning, see Zaky, 2014).

Under the scheme, one of the first of its kind in the Arab region, cash payments were transferred monthly to mothers and female heads of households, provided that they complied with certain child development goals in health and education (ESCWA, 2014:19). While this programme is an excellent example of a feminist approach to social protection (as 
it empowered women by recognizing their roles, aspiration and choices, including women's unpaid care work; see Sholkamy, 2011, 2014, for more details), it also combines lessons learnt in other CTs around the world on how to make such programmes more accountable. For example, with the aim of creating a relationship of reciprocity and equality between social workers and beneficiaries, several tools were developed. These included, first, a written contract with the rights and obligations of each party (that is, between citizens and the state) clearly spelled out, and which could serve as a point of reference for grievances. Presumably this is similar to Latin American conditional CT programmes, in which beneficiaries sign contracts of "co-responsibility", whereby they commit to availing themselves of basic services such as education, health and nutrition services; while the state in turn commits to ensuring adequate provision of these services (Fiszbein et al., 2009, cited in Jones et al., 2016:1209). A second tool was a calendar that enabled women to monitor their compliance to the conditions (and thus have evidence to argue against injustice). Third, a monthly monitoring checklist for use by the social worker was established. Lastly, the scheme set up a monthly group session for beneficiaries in which awareness of social rights was raised. These monthly sessions for groups of 30 women were devoted to rights-awareness and covered topics such as independent voting, micro-credit and indebtedness, housing rights, health and reproductive health (Sholkamy, 2011:3, 11, and 2014:130).

Interestingly, responding to the women's complaints that they were mistreated by service providers, the programme "stressed the role of social workers in supporting [them] to access existing services and to become more demanding consumers of these public goods and services" (Sholkamy, 2014:128). As Sholkamy (2014:129) points out, "the social worker provides support, information, clarifications, and a connection with the state."

This point illustrates the need for linkages between social protection and social accountability mechanisms such as community scorecard processes, in order for "social citizenship" to be realized. As Sholkamy (2011:8) explains, "while women are held accountable to governments for their households' uptake of education, health or other services, there is little accountability in the other direction. Women are often pushed into accessing poor quality services without voice or choice, in order to continue receiving what are usually very precious, yet small cash payments." She goes on to ask - presumably rhetorically: "Can women really be expected to take children to schools with no teachers or bad teachers? Or to visit clinics where doctors are absent or rude without empowering them to hold such failures to account?" (Molyneux, 2008; UNIFEM, 2008, cited in Sholkamy, 2011:8). In other words, not only should CT programmes themselves become more accountable, but for them to work, they rely 
on adequate service provision which in turn could be improved by SA processes such as CSCs.

The next section therefore considers some recent experiences with CSCs in the education and health sectors in the MENA region, which offer potential lessons for social accountability mechanisms within the social protection field.

\section{RECENT EXPERIENCES WITH CSCs IN THE EDUCATION AND HEALTH SECTORS IN THE MENA REGION}

CSCs are a community-based monitoring tool (usually facilitated by a local NGO) that assesses government performance in providing public services. Based on a joint analysis of qualitative data and scores obtained through focus group discussions with the community and a self-evaluation by the service providers, the process usually includes interface meetings between service providers and users to formulate a (public) action plan to address any identified problems and shortcomings (Grandvoinnet, Aslam and Raha, 2015:295-6). ${ }^{2}$

In terms of CSC outcomes, CARE International (Aston, undated:16; see also Wild and Wales, with Chambers, 2015:24; Grandvoinnet, Aslam and Raha, 2015:59-62) proposes three change typologies which lie on a continuum along three main levels (or tiers). The various experiences described below can be located along this continuum:

(1) Operational outcomes (instrumental changes). These relate to knowledge and attitudinal changes, and changes in the day-to-day practices of service users and service providers. These may include: greater knowledge and awareness of rights and entitlements; positive attitudinal changes around women's rights; positive attitudinal changes in service providers towards service users; greater transparency; and reduced petty corruption.

(2) Empowerment outcomes (relational changes). These are evidenced by user and provider changes in participation, voice, collective action, respect and trust. These may include: increased sense of selfconfidence on both sides; increased participation in public spaces; increased collective action by communities; perception of more respectful care by service providers; and a greater sense of understanding and trust between users and providers.

(3) Institutional outcomes (systemic changes), that is, facility and local government management changes. These may include: increased 
user satisfaction and utilization of quality services; increased district budget/allocation of equipment; increased staffing allocation; institution of quality assurance protocols; linkages to other services; and influence on sectoral policies.

While the literature is still limited, the work by CARE International to promote social accountability in the social sectors in the region is worth highlighting here. In November 2010, CARE International in Egypt and the World Bank organized the first regional workshop on social accountability, which led to the establishment of the Affiliated Network for Social Accountability in the Arab World (ANSA-Arab World). It was officially launched in Rabat in March 2012 and is managed by CARE International in Egypt as a project under the Governance and Civic Engagement Programme. It has been designed around four pillars, or key components of social accountability. First, access to information relates to the ability of citizens to see the information on which government decisions are made, that is, whether a basic law exists and to what extent it is adhered to. Second, budget transparency refers to the publication of public finance data in order for citizens to influence the allocation of public spending - be it at the stage of budget formulation, approval, execution and oversight. Third, freedom of association is needed for both organized civil society as well as the more decentralized youth movements and coalitions that emerged during the Arab Spring. Finally, service delivery refers to the ability to influence policy-makers and/or to participate in the management and implementation of services. For this, at least parts of the first three pillars need to be in place (Aston, undated:5-6).

On a practical level, during 2013-14, ANSA-Arab World allocated small grants (of US $\$ 25,000$ on average) to implement community scorecards to 11 civil society organizations (CSOs) across health, childcare, education, water and sanitation, and other services in the region (Aston, undated:5-8, 18-19). ${ }^{3}$ The findings reported here will focus on education and health as more "typical" social protection domains.

In its assessment of these grants (Aston, undated:9), CARE International - Egypt acknowledges the importance of the political and socio-economic context in understanding why very similar transparency and accountability mechanisms and processes have markedly different success rates, as evidenced by recent literature (see Bukenya, Hickey and King, 2012; O'Meally, 2013; Joshi, 2013; Grandvoinnet, Aslam and Raha, 2015; Lodenstein et al., 2016; for CARE's research with the Overseas Development Institute (ODI) on CSCs, see Wild and Wales, with Chambers, 2015).

For example, in Tunisia, a New Decree for Access to Information was passed in 2011, with the government also publishing financial (audit) 
reports. Similarly, the World Bank's Development Policy Lending to Tunisia has supported the adoption of a decree to institutionalize the mechanisms for participatory evaluation of public service performance (Grandvoinnet, Aslam and Raha, 2015:93-4; Brixi, Lust and Woolcock, 2015:308). Some CSOs have started to use SA tools, as for example giving awards to whistle-blowers, though the great majority of CSOs still lack experience and expertise to use such tools. In Jordan, while CSOs have become more active, most of them have a limited understanding of SA. In Morocco, the new constitution includes provisions for increased government accountability towards the citizens, but in practice these are still difficult to enforce. In Palestine, there is no right to access to information, and many Palestinians narrowly view SA to imply anti-corruption efforts. However, there is a fairly vibrant and active civil society and community-led monitoring and hearings are common practice. Yemen faces significant security challenges but there are many examples of citizen collective action, and a promising national dialogue. Finally, in Lebanon, institutional reform and financial transparency has been limited due to the persistence of sectarian and patronage ties between key political actors and private companies. Nevertheless, ANSA-Arab World members reported in November 2015 that there is increased openness on the part of government to listen to civil society actors (Aston, undated:20-3; for a much more detailed overview of the state of social accountability in MENA, see the baseline assessment conducted for ANSA-Arab World by Integrity Research and Consultancy (2013), Brixi, Lust and Woolcock (2015:chapter 5) and World Bank, 2011).

In addition, there is a growing literature on how sector-specific characteristics shape the spaces for citizen engagement and social accountability. ${ }^{4}$ Without reviewing this literature in detail, it is worth highlighting the importance of "political salience" as probably the foremost determinant of service provision. According to Batley and Harris (2014:7), "political salience" is understood broadly as the "incentive[s] for political leaders to provide services to those able to offer political (e.g. electoral) returns". In other words, it is essential to understand when and how political leaders and other power-holders weigh in on service delivery decisions (Aston, undated:11).

While education and health differ in some characteristics (see Harris et al., 2013, Harris, Batley and Wales, 2014), the differences are not as large as with some other sectors, such as water provision. In fact, the CSC experiences in these sectors under the ANSA-Arab World grant scheme noted quite a few similarities: "there is a clearly delineated frontline service user-recipient relationship and bureaucratic hierarchy (i.e. strict procedural mandates), [and] the emphasis of the [action] plan tends to be civic 
mobilization to engage in the functioning of services by either creating or renewing health and parent-teacher committees, or in resolving operational bottlenecks" (Aston, undated: 36). The bureaucratic hierarchies in the health and education sectors mean that issues of performance can be addressed in a more institutionalized fashion (for example, by providing competency guidelines or appeal to higher-up ministry officials to convince frontline staff). However, it is clear that the level of "decentralization of powers in each sector conditions which service providers or administrators are able to modify operational protocols, institutionalize new norms, shift behavioral trends, or shift resourcing" (Aston, undated:36).

Indeed, despite sectoral similarities, context-dependent and intervention-dependent variations were observed. First, with regard to education, the service providers (teachers) all faced similar issues such as low pay, high work pressure and long working hours. However, as the administrative apparatus varies considerably between countries, there is variation around which issues can be addressed as part of the CSC process and which ones cannot. For example, in Jordan, teachers are not allowed to receive cash allowances such as transportation allowances, which prevents them from attending events outside of the school. However, in one case in Jordan and a result of the CSC process, a permanent committee was established in a school which regularly unites the pupils, parents, teachers and administrators and enjoys more direct links with the Ministry of Education (Aston, undated:24-5), thus representing an institutional outcome in the typology presented earlier. In Yemen, the CSC identified the quality of school infrastructure and teacher performance as the key issues, which were then addressed in an action plan. Various stakeholders, such as donors and international organizations, alongside local authorities, committed to addressing the various issues related to the physical infrastructure, while the Provincial Education Office provided competency guidelines and a plan to cover teacher shortages in certain subject areas. These actions, which can also be seen as institutional outcomes of a CSC process, led to a significant increase in community satisfaction with services (Aston, undated:26). The CSC process in a vocational training centre in Casablanca, Morocco, led to the realization on the part of citizens that their own participation in school management was important, instead of only relying on the centre's own administration and administrative procedures. This then resulted in limited, but tangible gains, and arguably at least to instrumental, if not relational, changes (Aston, undated:26).

Second, with regard to CSCs in the health sector, one of the ANSAArab World experiences in Lebanon showed that such tools can contribute to relational changes by significantly increasing awareness on the part of service providers about their patients' concerns, and ensuring that 
service users were more aware of service providers' constraints (Aston, undated:27). In the other experience in Lebanon, health service providers were more reluctant to engage as they feared a process of "naming and shaming". A compromise solution was found whereby they made verbal commitments to support accountability efforts without signing a memorandum of understanding (MoU) with the service users, and the intermediary association (the ANSA-AW grantee) mobilized other local actors instead who could address some of the issues raised (for example, the Red Cross provided a four-wheel-drive car to reach underserved rural populations; Aston, undated:27-8). As Aston (undated:28) notes, "at the end of the project we began to note significant changes in service provision. With regards to users' empowerment, citizens had greater clarity on what public services they are entitled to receive, they became more aware of the value of their opinion, appeared less afraid to voice their views, and indeed [more aware of] how they can play a meaningful role in jointly improving services. [...] Coordination actions [i.e. involving other stakeholders than the direct service providers] were able to encompass issues beyond the scope of the action plans themselves." This is thus also an example of a CSC process contributing to empowerment outcomes and relational changes.

Aston (undated:28-9) also reports on a CSC experience in Egypt which shows the importance of providing other types of incentives to service providers when resource constraints prevent giving pay rises: the association (grantee) worked with hospital employees to persuade them that service users would "appreciate them" more if they participated. Similarly, the World Development Report 2015: Mind, Society, and Behavior, reports that simply reminding health workers, teachers, public servants and policy-makers of the social expectations of their performance can improve it (World Bank, 2015, cited in Brixi, Lust and Woolcock, 2015:302-3). As Brixi, Lust and Woolcock (2015:303) note, "in health facilities and schools, supportive supervision by peers, professional associations, and civil society organizations has been shown to contribute to sustaining norms of professional behavior, as have social cues in the form of recognition such as awards, token prizes (such as stars and plaques to display in the workplace), and small gifts (a book or pen)." In addition, a new civil service law includes "citizen satisfaction" as a crucial component of service providers' mandates (Aston, undated:28-9).

Hence, it is important to also pay attention to social accountability relations which emerged more or less organically, that is, outside the context of formal CSC processes. The examples discussed by Brixi, Lust and Woolcock (2015:chapter 3) include two schools in Jenin (West Bank) and Yarqa (Jordan), which thrive on well-functioning accountability relations, 
including active parent-teacher associations, and two examples in the health services in Jordan and Morocco. These examples suggest that such approaches are "indeed accepted positively by teachers and health workers, providing them with greater satisfaction at work and the motivation to meet the expectations of their students and patients as well as supervisors and the community at large" (Brixi, Lust and Woolcock, 2015:303).

Having provided a snapshot of some CSC experiences in the health and education sector in the region, we now turn to a discussion of what can be learnt from them for social protection programmes.

\section{DISCUSSION}

First, many CSC experiences highlight the scepticism on the part of service providers with regard to the benefits of their engagement in the process. As Aston (undated:36) points out, "this was not because they did not care about the quality of services, but rather because they were afraid of 'naming and shaming' and saw their primary accountability relationship to be to their supervisors [and not with service users]." Most service providers required authorization from their managers before they were able to engage in a meaningful way. For the NGOs facilitating the process, a solution was found in only rarely using the word "accountability" and instead promoting the participation of service users in school or facility management. There is clearly a risk that such a strategy leads to a situation in which the state is "absolved" from its responsibilities, and service users instead end up carrying the burden of ensuring adequate service provision (for example, parents' associations being responsible for school maintenance). However, the framing of the CSC process as allowing service providers to gain new skills and to begin to feel that they are appreciated partners also helped to gain their engagement. Similarly, the ANSA-Arab World CSC experiences show that "on various occasions, the 'rights' agenda did not sit easily with service providers, so the discourse and narrative often had to be reframed. Others spoke of 'ownership' and 'legitimacy'" (Aston, undated:38). Regardless of the language that is used, it is clear that SA mechanisms such as CSCs have the potential - both on the part of the providers as well as the users - to "change the perceptions of the responsibilities of the state as well as the perceived entitlements of citizens, both of which are fundamental to any 'social contract"' (Grandvoinnet, Aslam and Raha, 2015:11). However, there is a risk that programme implementers feel the need to tone down the rights discourse in order to get service providers "on board", thus sacrificing the potential gains in terms of CSCs providing spaces for citizenship struggles. 
Second, even if service providers are "on board" and committed to improving services, they may lack the mandate to mobilize more staff or leverage more resources. In this case, as Aston (undated:37) points out, "the CSC tends to act as an issue raising process but not necessarily an issue resolving process" (italics in original). In the ANSA-Arab World examples, the mobilizing of new resources (for example, for health centres and schools) catalysed by the scorecard process was "most often the result of coordination efforts with non-state actors such as the Red Cross and UNRWA rather than formal duty-bearers. However, ideally the priorities in the improvement plans should be connected to local planning frameworks" (Aston, undated:37). This echoes the point made above about the risk of SAIs contributing to letting the state "off the hook" when citizen and civil society participation is emphasized at the expense of accountability and social citizenship rights.

One remedy might be to increase the "political salience" of service provision, that is, to increase the incentives for local elected politicians to act as intermediaries between service providers and citizens by making them "feel that delivering promises will help bolster votes, or at least ensure broader legitimacy" (Aston, undated:38). The broader point here as made by Hickey and King (2016:1236) in the field of social protection is that the tendency to sidestep government delivery mechanisms can undermine the development of a social contract whereby social protection can become a "structural linkage" binding states and citizens and a medium for wider forms of bargaining. As they put it (ibid.) "from [a] social contract perspective, it makes sense to ensure that governments are closely involved in the distribution of social transfers and well placed to reap the political benefits such as increased legitimacy."

A case in point is Palestine's PNCTP in the West Bank and Gaza, which was discussed earlier. While the MoSA is involved in administering the transfers, it is not doing enough in the area of awareness-raising and information dissemination efforts to ensure that the Palestinian Authority (PA)'s contribution is recognized by the population. As Jones, Samuels and Malachowska (2013:53) put it, "this is effectively undermining the potential political mileage that could be gained."

Third, like any process of social change, the success of each initiative depends greatly on the prior relationships between the recipient CSOs, their partners and service providers, either at the frontline or with hierarchies in the sector (Aston, undated:36). Some of the CSOs in the ANSAArab World projects encountered barriers regarding political clientelism (opposition parties controlled the facilities or staff asked for money to collaborate; Aston, undated:37). The inverse scenario means that some of the CSOs spent a sizable proportion of the initiative raising awareness 
and building connections (Aston, undated:38). Similarly, the example of the CCT programme in Ain el-Sira in Cairo discussed earlier showed the importance of the role of social workers in mediating between the citizen and state officials and bringing them together in credible interfaces $-\mathrm{a}$ role which Grandvoinnet, Aslam and Raha (2015:42) refer to as "interlocution between the state and civil society".

Indeed, personal relationships and the role of interlocutors are something rarely discussed in NGO reports, which prefer to foreground strategy over connections. Yet, as Aston (undated:37) points out, it is abundantly clear from the cases above how important personal relationships are to advocacy efforts. These personal connections are linked to the idea of reform champions who are able to impel change beyond operational bottlenecks. Linked to this is the fact that for some of the CSOs, the CSC process provided a platform for advocacy beyond the scope of facility management (that is, outside of the mandates and resources of frontline providers). In both Jordan and Yemen the scorecard process was located within a broader advocacy campaign, and this undoubtedly increased the potential for higher-level changes (Aston, undated:37). The recently established CT beneficiary fora in the West Bank mentioned earlier could be considered a further example of an "interface" between service users and providers at a higher scale, facilitated by specially trained social workers. These findings resonate with those by Hickey and King (2016:1228) who note that 36 out of the 91 studies reviewed found that higher levels of state-civil society collaboration within accountability mechanisms translated into greater success.

This finding about personal connections points to a broader fundamental recent insight in the literature on the contextual drivers of social accountability, namely that "there is a need to go beyond the supply-demand, principal-agent, and state-citizen dichotomies in order to understand the more progressive and regressive coalitions that cut across the state and citizen divide and to support those that are conducive to state-citizen engagement and that drive greater accountability" (Grandvoinnet, Aslam and Raha, 2015:6).

However, for such coalitions to emerge, more time is needed than is generally the case with CSCs, which typically only last between 6 and 12 months. The limited time frame helps to explain why many of the changes are instrumental or related to improving equipment rather than relational or even systemic (Aston, undated:33). Those involved in the ANSAArab World experiences therefore argued that the CSC model should be repeated several times after the initial cycle in order to periodically measure progress on higher-level outcomes, and to allow for changes which require the buy-in, commitment and co-ordination between various actors (Aston, 
undated:39). Again, this confirms the finding that "the persistence of mobilisation over time also contributed to effective influence, suggesting it may be important to consider social accountability as the outcome of longer-term and iterative processes of bargaining between social and state actors, rather than one-off interventions" (Joshi and Houtzager, 2012, cited in Hickey and King, 2016:1228-9).

\section{CONCLUSION}

The aim of this chapter was to explore the conceptual and empirical linkages between social accountability, citizenship and social protection in the MENA region. While the evidence presented here is limited and not always positive, it provides some indication that including accountability mechanisms in CT programmes and using social accountability tools such as CSCs to improve services can contribute to community empowerment and the realization of social citizenship rights. Through repeated faceto-face interactions with local state representatives, ordinary citizens get opportunities to "see the state" (Corbridge et al., 2005, cited in Jones et al., 2016:1222), and to increase their awareness about eligibility and the scope of entitlements with the help of (ideally, non-politicized) community agents or social workers (Jones et al., 2016:1222-3).

In relation to one of the main themes of this book, namely the development in the MENA region of an integrated social policy package which is sustainable and scalable, the key challenge for social accountability approaches is their institutionalization beyond merely establishing monitoring and feedback loops between programme implementers and beneficiaries. As mentioned earlier, one of the potential outcomes of SAIs are institutional channels for state-society interaction, that is, the creation (or rejuvenation) of transparent and credible public interfaces between states and citizens that are missing or are not being used in various contexts. As they get used over time, such interfaces enter the institutional repertoire in people's minds, and the practice of participating in these spaces becomes an accepted part of civic life (Aiyar and Walton, 2014, cited in Grandvoinnet, Aslam and Raha, 2015:60).

The challenge for the MENA region is to provide incentives for state officials (elected or appointed) to agree to setting up and participating in such interfaces, rather than falling back into (neo-)authoritarian habits of co-optation (including of having civil society organizations doing the state's job), patronage or outright oppression of civic resistance. A possible avenue to address this challenge would be to bridge "the major disconnect between national legislation and commitments to citizen welfare and 
local implementation capacity, perpetuated by the under-development and underfunding of strategies to sensitise programme implementers and recipients about their rights and responsibilities", as identified by Jones, Samuels and Malachowska (2013:52). A major role for donors would therefore lie in funding programmes that raise awareness about such rights and entitlements, and the (legal) options to claim them in various spaces, be it at the regional, national or international level, in line with more critical approaches to citizenship. Doing so would also answer Joshi and Houtzager's (2012:158) call for a more deeply politicized, iterative understanding of social accountability as "watchdog", in which "the linkages that local collective actors [have] to national [and international] policy networks" are often key to success. A promising area for future research on social accountability in social protection policies in the MENA region lies precisely in exploring these linkages further.

\section{NOTES}

1. For a discussion on the distinction between transformative and non-transformative social protection interventions, see Molyneux, Jones and Samuels (2016:1088). The latter refer to interventions providing palliative measures that smooth over the effects of poverty (for example simple CTs or food aid programmes); whereas the former include those that aim to enhance the potential of poor people to move out of poverty (for example by investing in their capabilities, changing their behaviour and helping them to overcome disabling/ oppressive social relations) (ibid.).

2. See also "Community Scorecard" in the Social Accountability E-Guide. Available at: https:// saeguide.worldbank.org/sites/worldbank.org.saeguide/files/documents/1_Community\%20 Scorecard.pdf (accessed 8 August 2017).

3. These included the following CSOs: The Palestinian Center for Communication \& Development Studies, the Student Forum Institute (Palestine), the Amman Center for Human Rights, the Social Development Association (Jordan), the Yemeni Observatory for Youth, the Gateway Development Foundation (Yemen), the Auberge Beity Association (Lebanon), the Lebanese Center for Active Citizenship (LCAC), Al Choula for Education $\&$ Culture Association (Morocco), Youth of Change (Morocco), and Association du développement et des études strategiques de Medenine (ADESM - Tunisia). A 12th grantee, Al Ekhlas association in Egypt, was separately funded through CARE Egypt due to the inability to get approval from the Ministry of Social Affairs (Aston, undated:8-9).

4. See McLoughlin with Batley (2012), Batley and McLoughlin (2015) and Batley and Harris (2014). For a good discussion of the concept of social accountability, see Malena, Forster and Singh (2004).

\section{REFERENCES}

Aiyar, Y. and M. Walton (2014). "Rights, Accountability, and Citizenship: Examining India's Emerging Welfare State", Accountability Initiative Working Paper, New Delhi, October. 
Alami, R. (2016). "Health in MENA: Policies for Inclusive Development". In M.M. Erdoğu and B. Christiansen (eds), Comparative Political and Economic Perspectives on the MENA Region. Hershey, PA: Information Science Reference, pp. 125-49.

ANND (Arab NGO Network for Development) (2014). Social Protection in the Arab World: The Crisis of the State Exposed: Arab Watch Report on Economic and Social Rights, ANND.

Aston, T. (undated). "Towards Better Practice in Public Services Monitoring: Evidence from the Arab Network for Social Accountability Project”. CARE International Egypt, Governance and Civic Participation Program, The Affiliated Network for Social Accountability in the Arab World (ANSA-Arab World), World Bank Group. Available at: http://governance.care2share.wikispaces.net/file/view/ANSA $\% 20$ Review.pdf/594810202/ANSA\%20Review.pdf (accessed 4 August 2017).

Bagash. T., P. Pereznieto and K. Dubai (2012). "Transforming Cash Transfers: Beneficiary and Community Perspectives on the Social Welfare Fund in Yemen". UK AID and ODI. London: Overseas Development Institute.

Bagash. T., P. Pereznieto and K. Dubai (2013). "Cash Transfers: Perspectives on the Social Welfare Fund in Yemen”. Transforming Cash Transfers. Country briefing, UK AID and ODI. London: Overseas Development Institute.

Barca, V. (2015). "Grievance Mechanisms for Social Protection Programmes: Stumbling Blocks and Best Practice”. One Pager 320 (April), Brasilia: International Policy Centre for Inclusive Growth, UNDP.

Batley, R. and D. Harris (2014). "Analysing the Politics of Public Services: A Service Characteristics Approach". ODI and the University of Birmingham.

Batley, R. and C. McLoughlin (2015). "The Politics of Public Services: A Service Characteristics Approach". World Development, 74(October), 275-85.

Batniji, R., L. Khatib, M. Cammett, J. Sweet, S. Basu, A. Jamal, P. Wise and R. Giacaman (2014). "Health in the Arab World: A View from Within. 1. Governance and Health in the Arab World". The Lancet, 383(9914), 343-55.

Brixi, H., E. Lust and M. Woolcock (2015). Trust, Voice and Incentives: Learning from Local Success Stories in Service Delivery in the Middle East and North Africa. Washington, DC: The World Bank.

Bukenya, B., S. Hickey and S. King (2012). "Understanding the Role of Context in Shaping Social Accountability Interventions: Towards an Evidence-Based Approach". Report commissioned by the World Bank's Social Accountability and Demand for Good Governance Team. Final version, 28 June. Manchester: IDPM, University of Manchester.

Chambers, R. (2014). "Good Practices for Effective Participation in Social Protection Design and Implementation". UNRISD Resource Platform for Practitioners and Policy Makers Linking Social Protection and Human Rights, blog, 27 March. Available at: http://www.unrisd.org/80256B3C005BE6B5/search/7A7C8F4B1D5 C2E9BC1257CA80058501B (accessed 19 December 2016).

Cleaver, F. (2005). "Rethinking Agency, Rights and Natural Resource Management"”. In S. Hickey and D. Mitlin (eds), Rights-Based Approaches to Development: Exploring the Potential and Pitfalls. Boulder, CO: Kumarian Press, pp. 127-44.

Corbridge, S., G. Williams, M.K. Srivastava and R. Véron (2005). Seeing the State: Governance and Governmentality in India. Contemporary South Asia, 10. Cambridge: Cambridge University Press.

Devereux, S., A. McGregor and R.S. Wheeler (2011). 'Introduction: Social Protection for Social Justice”. IDS Bulletin, 42(6), 1-9, doi:10.1111/idsb.2011.42.issue-6. 
Engberg-Pedersen, L. and N. Webster (eds) (2002). The Name of the Poor: Contesting Political Space for Poverty Reduction. London: Zed Books.

ESCWA (Economic and Social Commission for Western Asia) (2014). "Participation and Social Protection in the Arab World". E/ESCWA/SDD/2014/ Technical Paper 7, 5 November. New York: United Nations.

Fiszbein, A., N. Schady, with F. Ferreira, M. Grosh, N. Kelleher, P. Olinto and E. Skoufias (2009). Conditional Cash Transfers: Reducing Present and Future Poverty. Washington, DC: The World Bank.

Fox, J. (2015). "Social Accountability: What Does the Evidence Really Say?" World Development, 72, 346-61.

Grandvoinnet, H., G. Aslam and S. Raha (2015). Opening the Black Box: The Contextual Drivers of Social Accountability. Washington, DC: The World Bank.

Green, M. (2012). "Co-producing Ineffective States: Social Knowledge and Social Citizenship in Africa and in Development". ESID Working Paper 14. Manchester: Effective States and Inclusive Development Research Centre.

Harris, D., R. Batley and J. Wales (2014). "The Technical Is Political: What Does this Mean in the Health Sector?" London: ODI.

Harris, D., R. Batley, C. McLoughlin and J. Wales (2013). "The Technical is Political: Understanding the Political Implications of Sector Characteristics for Education Service Delivery". London: ODI.

Hickey, S. (2011). "The Politics of Social Protection: What Do We Get from a 'Social Contract' Approach?”. Canadian Journal of Development Studies, 32(4), 426-38, doi:10.1080/02255189.2011.647447.

Hickey, S. and S. King (2016). "Understanding Social Accountability: Politics, Power and Building New Social Contracts". The Journal of Development Studies, 52(8), 1225-40, doi: 10.1080/00220388.2015.1134778.

Houtzager, P. and A. Joshi (2008). "Introduction: Contours of a Research Project and Early Findings". IDS Bulletin, 38(6), 1-9.

Integrity Research and Consultancy (2013). "Baseline Assessment of Social Accountability in the Arab World: Final Report". Conducted for the Affiliated Network of Social Accountability in the Arab World (ANSA-AW) and CARE Egypt.

Isin, E.F. (2017). "Citizenship Studies and the Middle East". In R. Meijer and N. Butenschøn (eds), The Crisis of Citizenship in the Arab World. Leiden: Brill, pp. 511-34.

Jawad, R. (2014). "Social Protection in the Arab Region: Emerging Trends and Recommendations for Future Social Policy”. Arab Human Development Report Research Paper Series. New York: UNDP. Available at: www.arab-hdr.org/pub

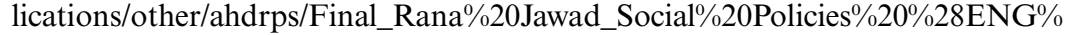
29.pdf.

Jones, N., B. Abu-Hamad, P. Pereznieto and K. Sylvester (2016). "Transforming Cash Transfers: Citizens' Perspectives on the Politics of Programme Implementation". The Journal of Development Studies, 52(8), 1207-24.

Jones, N., L. Maritano, G. Plank, B. Abu Hamad and K. Bani Odeh (2015). "Programme Evaluation of Tajaawob - Supporting Stability and Promoting Democracy in the Occupied Palestinian Territories (SSPD) programme". London: Overseas Development Institute.

Jones, N., F. Samuels, with A. Malachowska (2013). "Holding Cash Transfers to Account: Beneficiary and Community Perspectives". Transforming Cash Transfers, UK AID and ODI. London: Overseas Development Institute. 
Joshi, A. (2013). "Context Matters: A Causal Chain Approach to Unpacking Social Accountability Interventions". SDC-IDS Contribution: Providing Support to SDC's Democratization, Decentralization and Local Governance Network, Work in Progress Paper. Brighton: Institute of Development Studies. Available at: https:// www.ids.ac.uk/files/dmfile/ContextMattersaCasualChainApproachtoUnpacking SAinterventionsAJoshiJune2013.pdf.

Joshi, A. and P. Houtzager (2012). "Widgets or Watchdogs?" Public Management Review, 14(2), 145-62.

Kabeer, N. (2004). "The Search for Inclusive Citizenship: Meanings and Expressions in an Interconnected World". In N. Kabeer (ed.), Inclusive Citizenship. Meanings and Expressions. London: Zed Press, pp. 1-30.

Kabeer, N. (2014). "The Politics and Practicalities of Universalism: Towards a Citizen-Centred Perspective on Social Protection". European Journal of Development Research, 26(3), 338-54.

Karshenas, M., V.M. Moghadam and R. Alami (2014). "Social Policy after the Arab Spring: States and Social Rights in the MENA Region". World Development, 64, 726-39.

Lodenstein, E., M. Dieleman, B. Gerretsen and J.E.W. Broerse (2016). "Health Provider Responsiveness to Social Accountability Initiatives in Low- and Middle-Income Countries: A Realist Review". Health Policy and Planning (3 July), 1-16, doi: 10.1093/heapol/czw089.

Loewe, M. (2013). "Caring for the Urban Middle Class: The Political Economy of Social Protection in Arab Countries". In K. Bender, M. Kaltenborn and C. Pfleiderer (eds), Social Protection in Developing Countries: Reforming Systems. London and New York: Routledge, pp. 195-203.

Malena, C. with R. Forster and J. Singh (2004). "Social Accountability: An Introduction to the Concept and Emerging Practice". Social Development Papers: Participation and Civic Engagement, 74(December). Washington, DC: The World Bank.

Mansuri, G. and V. Rao (2013). Localizing Development: Does Participation Work? Washington, DC: The World Bank.

McGee, R. and A. Norton (2000). "Participation in Poverty Reduction Strategies". IDS Working Paper 109. Brighton: IDS.

McLoughlin, C. with R. Batley (2012). "The Effects of Sector Characteristics on Accountability Relationships in Service Delivery". ODI Working Paper 350. London: ODI.

Molyneux, M. (2008). "Conditional Cash Transfers: A Pathway to Women's Empowerment?". Pathways Working Paper No. 5. Brighton: IDS, Pathways of Women's Empowerment.

Molyneux, M., with N. Jones and F. Samuels (2016). "Can Cash Transfer Programmes Have 'Transformative' Effects?” The Journal of Development Studies, 52(8), 1087-98, doi: 10.1080/00220388.2015.1134781.

O’Meally, S.C. (2013). "Mapping Context for Social Accountability: A Resource Paper". Social Development Department. Washington, DC: The World Bank.

Sepúlveda, M. and C. Nyst (2012). The Human Rights Approach to Social Protection. Ministry for Foreign Affairs of Finland.

Sholkamy, H. (2011). "How Can Social Protection Provide Social Justice for Women?". Pathways Policy Paper (October). Brighton: Pathways of Women's Empowerment RPC.

Sholkamy, H. (2014). "Steady Money, State Support and Respect Can Equal 
Women's Empowerment in Egypt”. In J. Edwards and A. Cornwall (eds), Feminisms, Empowerment and Development: Changing Women's Lives. London: Zed Books, pp. 123-40.

Shukla, A., S. Saha and N. Jadhav (2013). "Community Based Monitoring and Planning in Maharashtra, India: A Case Study". Pune: SATHI and COPASAH.

Silva, J., V. Levin and M. Morgandi (2013). "Inclusion and Resilience: The Way Forward for Social Safety Nets in the Middle East and North Africa”. MENA Development Report. Washington, DC: The World Bank.

Taylor-Gooby, P. (2009). Reframing Social Citizenship. Oxford: Oxford University Press.

UNIFEM (2008). "Who Answers to Women?" Progress of the World's Women 2008/9. New York: UNIFEM.

Wild, L. and J. Wales, with V. Chambers (2015). "CARE's Experience with Community Score Cards: What Works and Why?". Synthesis Report. London: ODI and CARE.

World Bank (2011). "Supporting Social Accountability in the Middle East \& North Africa: Lessons Learned from Past Political and Economic Transitions". Washington, DC: Sustainable Development Department, Middle East and North Africa Region, The World Bank (November).

World Bank (2015). World Development Report 2015: Mind, Society, and Behavior. Washington, DC: The World Bank.

Zaky, H.M. (2014). "Does the Conditional Cash Transfer Program Empower Women? Evidence from Ain El-Sira, Egypt". Social Sciences, 3(4), 132-6, doi: 10.11648/j.ss.20140304.14. 